\title{
Perceptions and Practices of Dental Caries Prevention by Maryland Latinas: A Qualitative Study
}

\author{
Horowitz $\mathrm{AM}^{\star 1}$, Canto $\mathrm{MT}^{2}$, Goodman $\mathrm{H}^{3}$ and Child $\mathrm{W}^{4}$
}

${ }^{1}$ Research Associate Professor, School of Public Health, University of Maryland, College Park, Maryland, United States ${ }^{2}$ Public Health Dentist, Silver Spring, Maryland, United States

${ }^{3}$ Director of the Office of Oral Health, Department of Health and Mental Hygiene, Baltimore, Maryland, United States ${ }^{4}$ Independent consultant in College Park, Maryland, United States

${ }^{*}$ Corresponding author: Horowitz $\mathrm{AM}, \mathrm{PhD}$, Research Associate Professor, School of Public Health, University of Maryland, College Park, Maryland, United States, E-mail: ahorowit@umd.edu

Citation: Horowitz AM, Canto MT, Goodman H, Child W (2016) Perceptions and Practices of Dental Caries Prevention by Maryland Latinas: A Qualitative Study. J Dent Oral Care Med 2(2): 205. doi: 10.15744/24543276.2.205

Received Date: March 31, 2016 Accepted Date: May 11, 2016 Published Date: May 13, 2016

\begin{abstract}
Backgroud: In 2007 a young boy, Deamonte Driver, living in Maryland died from dental caries when the untreated infection spread to his brain. The immediate reaction by the state and community was to take steps to ensure that such an event never again occurs. A major activity was to conduct a state-wide oral health literacy needs assessment.
\end{abstract}

Objective: The purpose was to obtain in-depth information from low income Latinas about their understanding and use of dental caries preventive procedures.

Methods: Two focus groups (FG) were conducted in a professional focus group facility among Spanish speaking Latinas who were either pregnant or had a child six years of age or younger. The FG guide was developed based on one used with English speaking, low income women. The FG was conducted by a Spanish speaking facilitator.

Results: All women had little dental care as children and essentially none as adults in the US. There was lack of understanding about early signs of caries and knowledge of the importance of fluoride to prevent decay. Most women were concerned about the quality of drinking water and used bottled water for themselves and their children. One woman thought she should use bottled water to avoid fluoride.

Conclusions: These results provide additional evidence regarding the need to substantially improve oral health literacy of low income vulnerable populations regarding caries prevention. The information will be used to develop and implement educational interventions.

Keywords: Latinas understanding; Dental caries prevention; Immigrants

List of abbreviations: FG: Focus Groups consist of 8-10 individuals who provide their opinions on topics the researcher is interested in. FG are led by an experienced facilitator; WIC: Women Infants and Children is a program supported by the US Department of Agriculture that provides food stamps to low income women who are pregnant or have young children; Head Startc: is a preschool program sponsored jointly by the federal and state governments to prepare young children for school focusing on health and education

\section{Introduction}

Dental caries in primary teeth is the most common disease of childhood disproportionately affecting low income groups [1]. Latinos, the fastest growing population in the United States, tend to have lower levels of education and to be less likely than other groups to have visited a dentist in the past year [2,3]. Concomitantly, Latino children experience disproportionate rates of dental caries and are less likely than other groups to have had a preventive visit in the past year $[4,5]$. Further, caries in primary teeth varies by poverty status in that low income groups have 2 to 5 times more caries than high income groups [6]. Similar trends are found among children in Maryland [7]. Despite increased efforts in Maryland to prevent this disease, dental caries is one of the major health problems among low income children. The most recent dental survey indicated that Non-Hispanic Black and Hispanic children were significantly more likely to have had a history of dental caries than non-Hispanic white children [7].

Because parents are largely responsible for the health of their children, a statewide telephone study was conducted in 2010 among English speaking Maryland adults with young children. The results showed that these adults, especially those with low levels of education, are not very knowledgeable about how to prevent this disease and do not practice recommended preventive procedures [8]. 
Similar outcomes were found among rural Latino immigrant caregivers in California [9]. Additionally, several focus groups have been conducted among English speaking, low income Maryland parents of young children regarding dental caries prevention, however none has been reported among Latinas on this topic [10].

Very little is known about what Maryland Latina mothers or pregnant women understand about how to prevent or control dental caries. Because this disease can be prevented or managed with the appropriate use of fluorides and dental sealants and because mothers are usually responsible for the health of their children, it is important to learn what Latinas know and do about caries prevention. Thus the purpose of this study was to conduct focus groups to gain in-depth information about Latinas' understanding of preventing this nearly ubiquitous oral disease. This qualitative study was part of a statewide oral health literacy needs assessment.

\section{Materials and Methods}

Two focus groups were used for this qualitative study. The semi-structured moderator guide was based on one developed for English language FG. It was translated into Spanish by a Spanish speaking facilitator, modified for cultural sensitivity, reviewed by a Spanish speaking dentist (MTC), then back-translated into English for the research team's review. The Institutional Review Board, University of Maryland, approved the conduct of the study. Informed consent was obtained from each participant prior to the focus groups. To encourage participation, the groups were held at a focus group facility in a mall frequented by Hispanic families. Participants received an honorarium, toothbrushes and toothpaste for themselves and their children. Child-care was provided if needed.

To recruit women, Spanish language flyers were distributed by recruiters in various locations including churches, grocery stores, and community centers. The flyer explained the purpose of the focus groups and the opportunity to participate and gave a phone number to call if interested in participating. The recruiters approached and spoke with women in these locations urging them to call in. Women who called were then asked a series of questions to ensure each participant met inclusion criteria-being pregnant and/or having at least one child six years of age or younger, being Spanish-language dominant, and having a low income. Women were asked what level of education they had completed-primary (elementary), secondary (middle school), post-secondary (high school) and university. Once they agreed to participate, the focus group date, time and location were confirmed.

In July 2011, we conducted two focus groups ( $\mathrm{N}=16)$ with Latinas with the following characteristics: 1) 18-35-years of age; 2) Spanish-speaking; 3) either pregnant and/or who had a child 6-years of age or younger; 4) were of low income and 5) had a low level of formal education. Each focus group lasted about 75 minutes. The women were from one of four countries where Spanish is the primary language: Honduras, Peru, El Salvador or Guatemala.

The focus groups were conducted in Spanish by an experienced bi-lingual facilitator. A bilingual public health dentist (MTC) attended to ensure correct use of dental and other health terms by the facilitator and to translate for the principal investigator $(\mathrm{AMH})$. Topics included: participants' own experiences with dentists and frequency of going to a dentist as adults; awareness and understanding of how to prevent dental caries; awareness of what fluoride is and how it impacts oral health; awareness of how caries causing bacteria is transmitted; preventive practices for maintaining infants and children's oral health such as avoiding sugars; and frequency of dental visits for participants' children.

Each focus group was audiotaped, transcribed, translated and analyzed. A note taker also documented responses and feedback. Analysis of the data included several steps. Each session was transcribed and translated into English for review by the public health dentist, PI and facilitator. After the review the facilitator prepared a written summary of the sessions with selected quotes. The facilitator manually coded the data using qualitative content analysis, a method designed to analyze written, verbal or visual communication messages. This approach identifies themes with relevant quotes. The principal investigator, public health dentist and facilitator discussed and agreed on the themes.

\section{Results}

\section{Personal experience with dental care- Theme 1}

About half of the women said they had gone to a dentist as children only when there was a problem such as a toothache. Routine dental care was not considered important by their parents as evidenced by the comments below. As a result, only 2 women had seen a dentist before they were 8 years old, and by then, problems were serious enough to involve pain and sometimes extractions that often created negative associations with dentists. For example:

"Sólo me llevaban al dentista cuando tenía un problema." \{I was only taken to the dentist when I had a problem.\}

"Mis padres no le daban importancia ir al dentista." \{My parents did not think it was important to go to the dentist.\}

"Mi experiencia fue mala. No me gustan los dentistas. Me da miedo." \{My experience was bad. I do not like dentists. I am afraid.\}

"En mi país es una experiencia negativa, le arrancan los dientes si le duelen." \{In my country it [going to a dentist] is a negative experience, teeth are pulled out when they hurt.\} 
Participants cited cost as a major reason for not seeing a dentist themselves. Most said they have health and dental insurance only for their children.

"No voy al dentista porque no tengo dinero." \{I do not go to the dentist because I do not have money.

"El dinero...es lo más importante." \{Money...that is the most important thing.\}

When participants were asked if they would go to the dentist if they did have dental insurance, all of the women eagerly responded "yes". Most of the women - including the one who said she was afraid of dentists - stated that they would go to the dentist as often as recommended by the dentist.

There was discussion about oral health during pregnancy; only one woman recalled having gum problems during pregnancy. Upon probing, none of the women mentioned going to the dentist during pregnancy.

\section{Experience with their children's dentist-Theme 2}

Women were not aware of the recommendation that infants should go to the dentist when the first tooth appears or no later than his/her first birthday. If an age was mentioned, it was usually at least two years or older. Six participants who reportedly took their children for a dental visit said they were satisfied with their children's dentists and that they were very well treated by staff at the offices. They often used words such as "nice" and "clean" to describe the offices and "kind" to describe the people.

However, some of the women reported having some bad experiences. For example:

"No lo atendieron bien, medio lo vieron, ni le vieron los dientes." $\{[$ My son] had a bad dental service; they barely looked at his teeth. $\}$

One participant expressed strong dissatisfaction with her child's dentist. She said that the receptionist was rude to her; she waited a long time beyond her original appointment hour; and that she was upset that a dental assistant (sic), not a dentist, inspected her child's teeth.

\section{Awareness of basic oral health care/prevention-Theme 3}

At first participants sounded like they knew some basic information about oral healthcare for themselves and their children, including the importance of tooth brushing and flossing and early dental care for their children. However, upon further questioning suggested they had not really been counseled about how to prevent dental caries or if they had, had not heard or understood some of the most important concepts. For example: Most participants had never heard the word "fluoride" and none had heard of "fluoride varnish". Even women who reportedly had heard of fluoride generally did not know its use is to prevent dental caries. Only two women had heard the term "baby bottle tooth decay" but they did not know what it meant. A few participants mentioned that the pediatrician recommended not leaving the baby with a bottle all night - but they did not understand why that was recommended.

No participant understood that parents can transfer caries causing bacteria (vertical transmission) to their infants. All but two of the 16 participants remained silent at first when the group was asked about how infants acquire the bacteria that causes tooth decay. Participants' guesses included: by giving the baby a bottle of milk with sugar or another sweetener; from parents kissing kids on the mouth and when children use someone else's toothbrush when playing. No one had heard the terms "white spots" or "white spot lesions" or that these are early indicators of tooth decay and can be remineralized or healed.

\section{Awareness of recommended oral health practices- Theme 4}

Participants were asked to name one thing they can do to take care of their own oral health or their children's to prevent tooth decay. Everyone could identify at least one oral health practice that is correct, but it did not appear that these practices were understood and used by everyone on a regular basis. Responses included:

"Para prevenir las caries, no comer dulces en la noche. Lavar los dientes antes de dormir" (Do not eat candy at night to prevent cavities. Brush your teeth before going to bed.\} (Two women mentioned this.)

"Hay que limpiar las encías del bebé con un trapito." \{It is necessary to clean the baby's gums with a little cloth." (Four women said that they do this.)

"El dentista me dijo, después de la pacha hay que cepillarle los dientes." \{The dentist told me to brush his teeth after I bottle-feed the baby.\}

"Me recomendaron no dejarle el biberón con miel en la noche." \{It was recommended to me not to let the baby sleep at night with a bottle of milk with added honey.\}

"El cigarro pone los dientes amarillos, los debilita." \{Cigarettes stain teeth yellow and it weakens them.\}

"Me recomendaron llevarlo al dentista a los dos años." [It was recommended to take [my son] to the dentist at age two.\} 
All participants with children over age two said that they buy toothbrushes recommended for children. However, only four said that their children brush their teeth twice a day with adult assistance. The other women reported their child brushed their own teeth. Four women stated their children brushed only at bedtime.

\section{Fluoride and its role in preventing dental caries-Theme 5}

Most participants had not heard of fluoride and even those who had, did not understand its importance in caries prevention [14]. For example:

"He escuchado el fluoruro, pero no sé que es." \{I have heard of fluoride but I don't know what it is.

However, one woman did say:

"Fluoruro... eso es bueno para tus dientes." \{Fluoride...it is good for your teeth.\}

Two participants said that fluoride is in drinking water. But one woman thought that fluoride is the reason you should not drink tap water unless you filter out the fluoride. In fact, most women said that they and their children drink only bottled water - not tap water. Many were concerned about water safety. Comments included:

"A mi me dijeron que es mejor beber agua del filtro que agua de botella porque tiene fluoruro." \{I was told that it is better to drink filtered [tap] water than bottled water because it [tap water] has fluoride.\}

When asked if they have ever heard about the term "fluoride varnish", most said no and no one knew what it meant.

"El barniz, ¿no es el mismo que le llaman el esmalte?" \{Varnish, isn't that the same as enamel?\}

\section{Sources of oral health information-Theme 6}

Women identified a number of sources for the information they knew about taking care of their children's oral health. They said they learned from: a dentist or dental clinic, school, social worker, their mother, the hospital where their children were born, pediatrician and the Maryland Health Department [sic].

When participants were asked what other information they would like to have about taking care of their babies' teeth and preventing tooth decay, they said they were interested in learning more about other ways to prevent cavities besides brushing teeth every day. They wanted to know the correct way to brush their teeth; the best toothpaste for preventing cavities and general information about dental care. Participants said they would like to receive this information directly from a dentist, or through radio, pamphlets, or at a parent meeting. None of the women mentioned the use of the Internet or any social media.

\section{Ranking of Oral health among other concerns-Theme 7}

All participants agreed that dental health for their children is as important as other health issues. When participants were asked to rate oral health on a 10- point scale, 1 being least important and 10 most important, all participants responded 10. However, most did not seem to believe it was as important as general health or other health issues for themselves. Two women agreed that dental health is as important as other health issues but said that they do not have enough money to go to the dentist.

"Yo pienso que la salud dental no es tan importante como la general." \{I think dental health is not as important as general health. $\}$

"Estoy vieja para ir al dentista, uno no muere por un problema dental." \{I am too old to go to the dentist, you won't die from a tooth problem.\}

"Si no es una emergencia, no hay necesidad de ir al dentista." \{If it is not an emergency, there is no need to go to the dentist.\}

"Es igualmente importante, pero por dinero no podemos ir más con el dentista." \{It is equally important, but the lack of money prevents us from going to the dentist more often.\}

\section{Discussion}

Overall, most participants were somewhat knowledgeable about basic oral health practices for themselves and their family members. Several women were aware of the importance of visiting a dentist regularly and taking their children to the dentist at a young age. But few recognized the recommendation for an age one dental appointment. Currently, many health providers (physicians and dentists) recommend older ages for the first dental visit or do not mention the need at all. Most women believed, incorrectly, that dental caries can be prevented by going to the dentist and were not aware of what they can do to prevent this disease in their own mouths and the mouths of their children. These results reinforce the need to increase oral health literacy through education of all health care providers, especially pediatricians and family practice physicians and staff regarding the need for them to counsel mothers about caries prevention and apply fluoride varnish. Because these women were more likely to take their child to a physician than to a dentist, focusing on medical providers may be pivotal to increasing oral health literacy and oral health. 
These results are similar to those found in English speaking focus groups in Maryland, although the lack of knowledge and understanding about caries prevention is more profound among the Spanish speaking women [10,11]. Concomitantly, the women in this study were extremely interested in learning about how to keep their children caries free which was addressed during the debriefing after the focus groups concluded.

In Maryland, over 90 percent of the central water supplied is optimally fluoride at $0.7 \mathrm{ppm}$. Yet, participants were not aware of the term "fluoride". Two respondents had a vague idea of the importance of fluoride for protecting their teeth from dental caries in connection with brushing teeth with fluoride toothpaste. It is noteworthy that the respondents did not recognize that their drinking tap water is not only safe, but also contains fluoride which prevents tooth decay. None of the participants knew about any kind of fluoride treatment for children and had never heard the term "fluoride varnish." The need is evident for a state-wide concerted effort to reach Spanish speaking families regarding the availability of fluoride varnish and how they can obtain it for their children. These findings are similar to other surveys or focus groups of Latinas in the U.S. indicating that the lack of knowledge and understanding about fluoride and it benefits is widespread $[9,12,13]$. This lack of knowledge suggests strongly that all groups who interact with these families-- medical and dental providers, preschool groups such as WIC and Head Start staff-- must be educated and subsequently spend time on the topic with their Spanish speaking patients. These are missed opportunities to educate immigrant families. These findings provide the basis for and incentive to developing educational materials and interventions specifically aimed at Spanish speaking pregnant women and those with young children. Because of the growing population of Latino immigrants, and because bottled water is expensive and detrimental to the environment it is critical that we educate adults and children that community water is not only safe but in communities that are optimally fluoridated it also provides caries preventive benefits.

Additionally, given the fact that none of the Latinas reported getting dental treatment during pregnancy, we need to focus on ensuring they understand their eligibility to do so and to assist them in finding care. Optimal oral health of women is especially important because of the material-child transmission of oral bacteria and the potential associated risk for dental caries [14,15].

Most participants indicated having good experiences with their children's dentist and mentioned that they would like to receive more information about how to have good oral health for themselves and their children. However, the one woman who was adamant about how poorly she was treated by a Latina receptionist is a reminder that a health literate health organization is one that makes it easier for people to navigate and use information and services rather than creates barriers [16]. Perception of discrimination by parents whose child is covered by Medicaid is not unique to this study as others have documented similar problems $[17,18]$. These findings reinforce the importance of cultural competency training, communication skills and the need for health facilities to be 'user friendly'. Finally, many participants thought dental health is as important as general health for their children but admitted to not paying enough attention to their own dental health. It was clear however that given the opportunity these parents would seek dental care for themselves. They identified lack of money or insurance to pay for dental visits as the major barrier to personal dental care.

\section{Conclusions}

The findings from this qualitative study will be instrumental in developing a questionnaire to conduct a statewide survey of Spanish speaking adults to learn more about what they know and do to prevent dental caries and for developing educational materials specifically for this population. This qualitative study of Latinas provides additional evidence about Maryland adults' limited understanding about how to prevent dental caries. Among this group of Latinas there was extensive misunderstanding of how to have healthy mouths for themselves and their children. These results combined with the focus groups conducted among English speaking women and statewide surveys make clear the need for major educational interventions at all levels and opportunities to prevent this nearly ubiquitous disease especially among this very vulnerable and growing population.

\section{Post Script}

Following the focus groups, the PI with the public health dentist interpreting answered additional questions the women had to dispel myths and incorrect information the women had about oral health. All participants were interested in and eager to talk about the topic of good oral health and asked numerous questions especially about fluoride and what kind of toothpaste to use. Equally interesting is all of the staff at the facility including the facilitator all of whom were Spanish speaking eagerly joined us in the debriefing.

\section{Acknowledgment}

This study was supported by a grant from the Maryland Department of Health and Mental Hygiene.

\section{References}

1. US Department of Health and Human Services (2014) Oral Health in America: A Report of the Surgeon General. Rockville, MD: US Department of Health and Human Services, National Institute of Dental and Craniofacial Research, National Institutes of Health, 2000. NIH Publication 00-4713.

2. United States Census Bureau (2013) Educational Attainment of the Population 18 Years and Over, by Age, Sex, Race, and Hispanic Origin: 2013 from the Current Population Survey, 2013 Annual Social and Economic Supplement [Data File]. 
3. O'Hara B, Caswell K (2013) Health status, health insurance, and medical services utilization: 2010. Curr Population Report 70-133.

4. Dye BA, Arevalo O, Vargas CM (2010) Trends in paediatric dental caries by poverty status in the United States, 1988-1994 and 1999-2004. Int J Paediatr Dent 20: $132-43$.

5. Vargus CM, Monajemy N, Khurana P, Tinanoff N (2000) Oral Health status of preschool children attending Head Start in Maryland, 2000. Pediatr Dent 24: 257-63.

6. Fisher-Owens SA, Isong IA, Soobader MJ, Gansky SA, Weintraub JA, et al. (2013) An examination of racial/ethnic disparities in children's oral health in the United States. J Public Health Dent 73: 166-74.

7. Macek MD, Coller S, Chen H, Manski RJ, Manz M, et al. (2013) Oral health survey of Maryland school children, 2011-2012. Baltimore, MD: University of Maryland School of Dentistry.

8. Horowitz AM, Kleinman DV, Wang MQ (2013) What Maryland adults with young children know and do about preventing dental caries. Am J Public Health, 103: e69-76.

9. Horton S, Barker JC (2008) Rural Latino immigrant caregivers' conceptions of their children's oral disease. J Public Health Dent 68: $22-9$.

10. Buerlein JK, Horowitz AM, Child WL (2011) Perspectives of Maryland women regarding oral health during pregnancy and early childhood. J Public Health Dent 71: 131-5

11. Horowitz AM, Kleinman DV, Child W, Maybury C (2015) Perspectives of Maryland adults regarding caries prevention. Am J Public Health 105: e58-64.

12. Scherzer T, Barker JC, Pollick H, Weintraub JA (2010) Water consumption beliefs and practices in a rural Latino community: Implications for fluoridation. J Public Health Dent 70: 337-43.

13. Hobson WL, Knochel ML, Byington CL, Young PC, Hoff CJ, et al. (2007) Bottled, filtered, and tap water use in Latino and non-Latino children. Arch Pediatr Adolesc Med 161: 457-61.

14. Chaffee BW, Gansky SA, Weintraub JA, Featherstone JDB, Ramos-Gomez FJ (2014) Maternal oral bacterial levels predict early childhood caries development. J Dental Res 93: 238-44.

15. Da Silva Bastos VDA, Freitas-Fernandes LB, da Silva Fidalgo TK, Martins C, Mattos CT, et al. (2015) Mother-to-child transmission of Streptococcus mutans: A systematic review and meta-analysis. J Dent 43: 181-91.

16. Brach C, Dreyer B, Schyve P, Hernandez LM, Baur C et al. (2012) Attributes of a health literate organization. Institute of Medicine.

17. Cortés DE, Réategui-Sharpe L, Spiro A, García RI (2012) Factors affecting children's oral health: Perceptions among Latino parents. J Public Health Dent 72: 82-9.

18. Mofidi M, Rozier RG, King RS (2002) Problems with access to dental care for Medicaid-insured children: What caregivers think. Am J Public Health 92: 53-8.

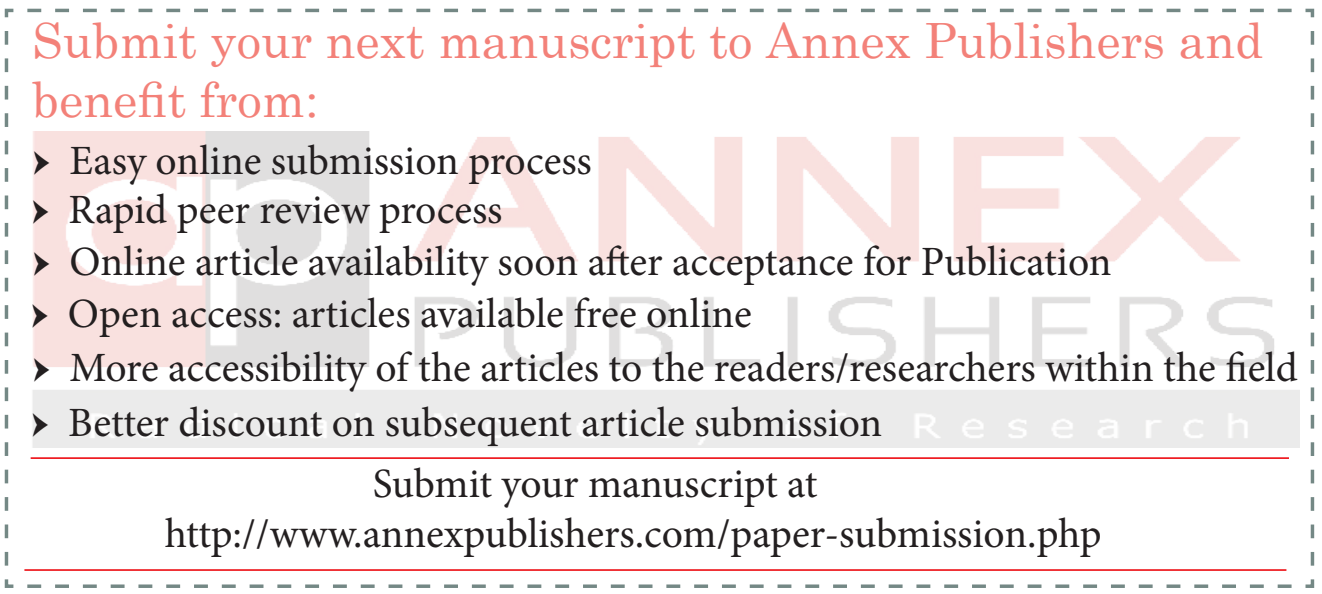

